\title{
Die Leistungsverfügung im niederländischen, deutschen und europäischen Zivilprozessrecht
}

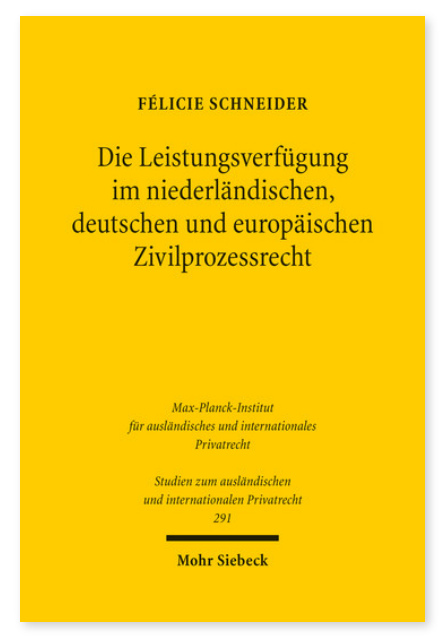

2013. XXIII, 436 Seiten. StudIPR 291

ISBN 978-3-16-152167-6

DOI 10.1628/978-3-16-152167-6

eBook PDF $94,00 €$

ISBN 978-3-16-151992-5

fadengeheftete Broschur 94,00€
Im internationalen Rechtsverkehr ist oft nur schneller Rechtsschutz effektiv. Das schlagkräftigste, aber auch gefährlichste Instrument des grenzüberschreitenden einstweiligen Rechtsschutzes stellen Leistungsverfügungen dar. Besonderer Beliebtheit erfreut sich in diesem Zusammenhang das niederländische kort geding. Um eine angemessene Risikoverteilung der Interessen von Gläubiger und Schuldner bemüht, entwickelte der EuGH in seinen Entscheidungen van Uden und Mietz spezielle Voraussetzungen für einstweilige Maßnahmen, die in ihrer praktischen Umsetzung für den Rechtsanwender im Anwendungsbereich der Europäischen Gerichtsstands- und Vollstreckungsverordnung (EuGVO) eine Reihe von Fragen aufwerfen. Félicie Schneider stellt dar, warum sie eine Präzisierung der richterrechtlichen Anforderungen für Leistungsverfügungen unter besonderer Berücksichtigung des niederländischen kort geding auch im Hinblick auf die anstehende Reform der EuGVO für geboten hält.

Félicie Schneider Geboren 1979; Studium der Rechtswissenschaften in Kiel, Liège und Maastricht; Referendariat beim Hanseatischen Oberlandesgericht Hamburg mit Stationen in Hamburg, Berlin und Brüssel; Richterin in Hamburg.

Jetzt bestellen:

https://mohrsiebeck.com/buch/die-leistungsverfuegung-im-niederlaendischen-deutschen-und-europaeischenzivilprozessrecht-9783161521676?no_cache=1

order@mohrsiebeck.com

Telefon: +49 (0)7071-923-17

Telefax: $+49(0) 7071-51104$ 